Laboratorio de Arte,1-1988 http://dx.doi.org/10.12795/LA.1988.i01.09

\title{
EL SAGRARIO DE LA CARTUJA DE LAS CUEVAS
}

Jorge Bernales Bällesteros

Las tareas de escultura hechas por Pedro Roldán para el Sagrario de la cartuja sevillana de Santa María de Las Cuevas, se conocían literariaménte gracias a las noticias de Palomino, pero las vicisitudes del cenobio covitano durante el siglo XIX tuvieron como consecuencia que se desmontasen del lugar para el que se habían hecho y se dieran por perdidas. En 1958 M. Elena Gómez Moreno se lamentaba de ello y decía en su historia de la escultura española del siglo XVII "...nada sabemos de su labor en la cartuja de Jerez, ni tampoco del sagrario con relieves, realizado, según Palomino, para la cartuja de Las Cuevas" (1). Sin embargo, los trabajos que hemos efectuado en los últimos años en diferentes monumentos de la provincia de Cádiz, nos han permitido localizar los citados relieves y precisamente en la iglesia de la cartuja jerezana de Santa María de la Defensión, donde están colocados también en la pequeña capilla, detrás del altar mayor, que, como es usual. en los templos cartujanos, hace las veces de Sagrario. Los mencionados relieves de Roldán, con sus estructuras arquitectónicas y decoraciones de carácter retablístico de Bernardo Simón de Pineda, se habian conservado en una dependencia del antiguo convento de Sevilla, convertido después de la desamortización de Mendizábal (1835) en fábrica de cerámica y lozas denominada "La Cartuja", propiedad de la familia Pickman. En 1948 uno de los propietarios regaló los relieves al Padre Arteche, renovador de la cartuja jerezana, quien los trasladó a su monasterio y encomendó su restauración al escultor Rafael Barbero, a fin de que decorasen el sagrario que debía reinstaurarse en el gran templo reconstruido gracias a su tesón y generosa ayuda del Cardenal Segura, así como la de familias notables de Jerez, Sevilla y Sanlúcar de Barrameda. En páginas posteriores se hará la descripción de esta

(1) Gómez Moreno, M. E.: Escultura del siglo XVII. Ars. Hispaniae. Vol. XVI. Madrid, 1958, Pág. 
joya del arte sevillano del siglo XVII, de la época del mejor barroco de esta escuela, pues la belleza de su misterioso interior y acertada restauración, convierten este recreado recinto en uno de los más expresivos ejemplos de lo que sin duda fue el esplendoroso conjunto de la cartuja de Las Cuevas.

Las noticias históricas referentes al Sagrario de este monasterio datan de 1436 y son recogidas por Cuartero (2) en su historia de dicha comunidad y convento, situado en las afueras de Sevilla y próximo a las huertas del arrabal de Triana. Según costumbre de la Orden, quizá por inspiración de la cartuja de Grenoble, los sagrarios suelen situarse en la cabecera de los templos, detrás del altar mayor, como lugar reservado y "Sancta Sanctorum" de todo el recinto sacro. El P. Rodriguez Gutiérrez de Cebalos estima que los sagrários cartujanos son por antonomasia las más rancias creaciones de sagrarios por lo que tienen de espacio independiente y enigmático; los considera como creaciones españolas y afines a esa inclinación monacal a la soledad, lo que habría animado a los monjes a disponer sus sagrarios en soledad, ocultos, y, dentro de ellos, Jesús Sacramentado, también oculto y hurtado a la vista del pueblo como el cartujo mismo (3). Estas creaciones de los monasterios hispanos de monjes cartujos, serían anteriores a las capillas del sagrario que proliferaron en Andalucía y América después del Concilio de Trento y a los transparentes barrocos de las catedrales, como igualmente lo advierte Bertos Herrera (4).

En la cartuja de Las Cuevas, construida en el s. XV, se dispuso también, detrás del primitivo retablo mayor (en 1436), un pequeño sagrario para el que se rompió - según los protocolos cartujanos del P. Rincón, recogidos por Cuartero- la pared maestra de la cabecera de la capilla mayor, entre dos estribos, de manera que se formó un pequeño espacio o capilla cuadrangular con respetable altura e iluminado por una claraboya en la parte superior del muro que hacía las veces de testero. Este recinto se engalanó con yeserías, pavimento de azulejos enlozados - de probable aspecto mudéjar-y se colocó al centro una custodia de plata labrada en forma de chapitel y tabernáculo con puerta de madera (5). En 1467 se estrenó el nuevo retablo

(2) Cuartero y Huerta, B.: Historia de la Cartuja de Santa Marfa de Las Cuevas de Sevilla y de su filial de Cazalla de la Sierra. Madrid, 1988. T. Il. Págs. 603 y 615.

(3) Rodriguez Gutiérrez de Ceballos, A.: Lectura iconografica del Sagrario de la Cartija de Granacta. Estudios sobre Literatura y Arte dedicados al Profesor Emilio Orozco. Vol. III. Universidad de Granada, 1979.

(4) Bertos Herrera, M. P.: La Eucaristla en el arte de Granada. Granada, 1985. T. I. Pág. 105.

(5) V. P. D. José Martín Rinoon: Protocolos del Monasterio de Nura. Sra. Santa Maria de las Cuevas. Tomo primero: Anales de los tres primeros siglos de su fundación..., arto de 1400 en que la fundb y dolb... Ano de 1744. Manuscrito inédito conservado en la Biblioteca de la Real Academia de la Historia. Madrid. Fol. 168. 
mayor, donado por el rey Alfonso $\mathrm{V}$ de Portugal, pero no se alteró el sagrario, lo que tampoco ocurrió cuando este retablo gótico fue sustituido por el de carácter renacentista que se empezó en 1542 y terminaron de 1557 a 1563 Isidro de Villoldo y Juan Bautista Vázquez el Viejo, aun cuando no se finalizaron las tareas de pintura y dorado hasta 1566 (6).

La suntuosidad del nuevo retablo alentó a los monjes a efectuar algunos arreglos para mejor ornato del sagrario, de modo que aún cuando no se cambió su estructura, sí se enriqueció con reliquias traídas de Roma y láminas de miniaturas probablemente pintadas sobre cobre y lienzos de pequeños formatos. Estas tareas se efectuaron en 1591, durante el priorato del P. Cristóbal Calvo.

El Abad Gordillo conoció este sagrario y en 1633 lo describió como capilla que estaba detrás del altar mayor, a la que se acudía por dos puertas de un estado de alto, por donde se servía el altar mayor, de manera que no entraba nadie en este recinto, el cual estaba muy bien aderezado y guardado; comenta que era pequeño, pero de muy curioso adorno y que ahí se levantaba el monumento del Jueves Santo con "lindos aderezos", en día que sí podía ser visitado (7).

En 1676 durante el priorato del P. Diego de San José (de 1670 a 1678), se decidió la comunidad a emprender una reforma sustancial, pues el recinto medieval dedicado a sagrario resultaba estrecho y de mezquinas proporciones para la monumentalidad que había adquirido este monasterio. El mencionado Prior tuvo fama de emprender obras de altos costos, tanto en el convento como en las propiedades que tenían los monjes en explotaciones, y algunos de estos empeños fueron considerados como no muy necesarios y de cierto riesgo, por lo que se le privó del priorato en 1678.

Después de los exitosos trabajos realizados conjuntamente por el arquitecto-ensamblador Bernardo Simón de Pineda y el escultor Pedro Roldán en las fiestas en honor de la Beatificación de San Fernando (1671) y grandioso retablo de la iglesia de La Caridad (1670-1673), adquirieron justa fama de ser los artistas más insignes de Sevilla en sus respectivas especialidades y así fueron convocados por las más importantes instituciones de la ciụdad. La cartuja de Las Cuevas, que durante el s. XVII tuvo una época de auténtico

\footnotetext{
(6) Idem. Fol. 455.

(7) Sánchez Gordillo, A.: Sumaria relación del insigne monasterio de Santa Marla de las Cuevas de Sevilla del Orden de la Cartuja. Compuesta en 1633 por el Lcdo... Edición de José M.a Yázquez Soto. Sevilla, 1987. Pág. 25.
} 
esplendor, encargó obras a los artistas más cualificados, y por ello, quizá, solicitó de Pineda y Roldán que, hiciesen un nuevo sagrario. Para la construcción del nuevo sagrario se derribó el muro existente y se amplió el recinto en otro tanto igual fuera de los fundamentos, de modo que se duplicó el espacio original reservado para sagrario y se elevaron nuevos muros que lo cerraron como "Sancta Sanctorum", con sólo los dos accesos laterales que a través de angostos pasillos conducían a las puertas del retablo mayor. Comenta el protocolo de estos años - compilado por el P. Rincón- que "...el noble arte de la escultura y relieve, apenas podía adelantar un punto a el arte que echó el insigne Pedro Roldán en sus efigies; en la talla y ensamblaje aportó su habilidad el célebre Bernardo Simón de Pineda y en el dorado y estofado Miguel de Parrilla que a este efecto fue traído de Málaga su patria" (8); se añade incluso el comentario de que se consiguió un interior con "piezas únicas, de gran belleza y deleite", que recubrian todas las paredes, realzadas por un pavimento de ébano y plata. Bemardo Simón de Pineda hizo las estructuras y decoraciones arquitectónicas, como si se tratara de un retablo y Pedro Roldán las esculturas de relieves de alegorias eucarísticas y ángeles que invadían todos los elementos de soportes y cubierta. Las tareas pictóricas de Parrilla fueron correctas y similares a las de cualquier otro pintor dorador de Sevilla.

Al tiempo que se hacían estas reformas en el sagrario, los citados artistas se encargaron de hacer retablos y esculturas para las capillas vecinas de La Inmaculada Concepción, San Hugo y San Antelmo. El costo total de estas obras fue de 200.000 reales, según los mencionados protocolos del P. José Rincón, consultados por Cuartero y el Marqués de San José de Serra (9).

Roldán era ya conocido en este monasterio por sus trabajos de yeserías y esculturas en la media naranja de la sacristía y marcos de los vanos, realizados en 1655 durante el priorato del P. Blas Domínguez a un costo de 17,000 reales (10); estas labores son, de momento, de las más antiguas de su producción en Sevilla, mientras que las del sagrario que se comenta pertenecen a su período de plenitud y son de lo más expresivo de su plástica barroca. Es posible que también proceda de 1676, el Crucificado de marfil que se atribuye al Maesíro, que hasta hace pocos años se guardaba en la capilla denominada del reservado y que, tal vez, estuvo antes en la sacristía.

(8) José Martín Rincón: Op. cit. Fol. 656 y 657.

(9) Marqués de San José de Serra: Los cuadros del Monasterio de Las Cuevas. Fecha en que los pinto Zurbarán". "Archivo Hispalense". T. XIII. Sevilla, 1950. Págs. $209-214$.

(10) José Martin Rincón: Op. cit. Fol 644. 
En 1697 el interior del sagrario se enriqueció con una custodia de plata que el Prior Fabián Ruiz de Anaya encargó al platero Juan Laureano de Pina por un costo inicial de 33.240 reales, aunque al ser terminada en 1698 alcanzó la cifra de 67,440 reales y un peso de cuatro arrobas y media, según datos que se consignan en los mencionados protocolos cartujanos, los que, además, dan la noticia de que en ese año de 1698 se contrató la hechura de una nueva sillería de coro con el maestro escultor Agustín de Perea.

Durante el siglo XVIII las referencias al sagrario como lugar de delicadas facturas artísticas es comentado por varios autores, entre los que destacan los del pintor Antonio Palomino y los religiosos cartujos P. Fernando Pantoja y el ya citado P. José Martín Rincón. El primero de estos autores, el pintor y tratadista Antonio Palomino de Castro y Velasco, publicó en 1724 las vidas de los pintores y estatuarios españoles - como continuación de su tratado pictórico- y al ocuparse de la biografía de Pedro Roldán menciona levemente los trabajos de relieves con historias que hizo para el sagrario de la cartuja de Sevilla (11).

El P. Fernando Pantoja escribió una relación de la obra del sagrario de 1676 con descripción de sus más notables piezas y alhajas, manuscrito de mediados del siglo XVIII que cita el P. Cuartero (12), pero que no ha sido posible localizar, debido a los deficientes datos que proporciona. Habría sido interesante consultar este escrito, si bien, de momento, no se ha encontrado bajo este autor y título ni en la Biblioteca Nacional ni en la Real Academia de la Historia, De mayor extensión en cuanto a noticias históricas del cenobio y las obras que se realizaron desde su fundación y durante más de tres siglos, es el manuscrito del P. José Martín Rincón, fechado en 1744 y que hemos consultado minuciosamente en la citada Academia. El manuscrito es de gran interés por las noticias que contiene y por los dibujos hechos a pluma que son de retratos de los priores más importantes, así como las obras de mayor relevancia; Cuartero estima que son de Pedro Duque Comejo, aunque no hay documentos que permitan confirmar tal atribución.

Arana de Varflora en su Descripción de Sevilla (1766) no menciona el Sancta Sanctorum covitano, aunque sí elogia dos miniaturas - que destaca por su gran belleza- que se hallaban en el "relicario", que, quizá, podría ser una alusión al dicho sagrario, pues en todas las demás referencias conocidas se

(11) Palomino de Castro y Velasco, A.: El Parnaso espanol pintoresco y Laureado. Madrid, 1947. Págs. 1.080 y 1.081 .

(12) Cuartero y Huerta, B.: Op. cit. T. I. Pág. 58. 
dice que en este recinto existían numerosos relicarios, si bien es impreciso y breve el comentario que hace del monasterio en general (13). D. Antonio Ponz sí escribe elogiosamente las obras de la Cartuja, pero no hace alusión expresa del sagrario, salvo la calidad de las dos miniaturas del "relicario" que, al igual que Arana de Varflora, destaca sobre muchas otras obras del templo y sacristía (14).

D. Juan Agustín Ceán Bermúdez y D. Antonio M." Espinosa son más explícitos y vuelven a citar las obras de artistas señalados que existían en el monasterio. El Diccionario histórico de Ceán, publicado en 1800, cita a Bernardo Simón de Pineda y a Pedro Roldán como autores del adomo y esculturas del sagrario (15), aunque no los describe ni comenta su importancia artística como hace en otras ocasiones. Por su parte, Espinosa y Cárcel en sus "Memorias cartujanas" (manuscrito de finales del s. XVIII), también cita las obras realizadas en el gran monasterio y hace indicación de la suntuosidad del sagrario con las circunstancias de su renovación. El P. Cuartero consiguió consultar el manuscrito de Espinosa en la Biblioteca del Duque de T'Serclaes, y gracias a la descripción que hace, sabemos que era un espacio de tres varas en cuadro, con tres testeros de madera dorada que figuraban altarcitos con relieves que representaban: la Ultima Cena, las Bodas de Caná y otros con alusiones a la Eucaristía, ejecutados por Pedro Roldán, y que en el testero principal estaba la custodia labrada por Juan Laureano de Pina sobre una mesa de altar con frontal de plata; añade que el pavimento era de ébano con incrustaciones de plata y que las puertas de acceso eran de cristal (16).

También D. Justino Matute y Gaviria elogia el sagrario y da con claridad los nombres de sus autores y la fecha en que se hicieron (17). Al parecer, Matute escribió estas notas antes de 1810 y guardó numerosos datos de documentos que vio y estudió en el archivo y biblioteca del monasterio, así como otros del palacio arzobispal, pues tenía intenciones de hacer una historia de ese monumento que no pudo efectuar por falta de tiempo, como lo expresa en sus "Adiciones y correcciones" a la descripción de Sevilla de D. Antonio Ponz.

(13) Arana de Vartlora. F.: Compendio historico descriptivo de la muy noble y muy leal Ciudad de Sevilla metrópoli de Andalucla. Sevilla, 1978. Pág. 50.

(14) Ponz, A.: Viaje de Espana. T. VIII. Madrid, 1784. Pág. 234.

(15) Ceán Bermúdez, J. A.: Diccionario Histórico de los más ilustres Profesores de Las Bellas Artes. T. IV Madrid, 1800. Pág. 99 y 244.

(16) Cuartero y Huerta, B.: Op. cit. T. Il. Pág. 613.

(17) Matute y Gaviria, J.: Adiciones y correcciones al tomo IX del Viaje de Esparta por D. Antonio Ponz. "Carta V". "Archivo Hispalense". T. IV. Sevilla, 1888. Pág. 184. 
En todos estos comentarios se describe la monumentalidad y riqueza del cenobio covitano, lo que permite rastrear su estabilidad y esplendor artístico hasta los primeros años del siglo XIX. Sin embargo, los acontecimientos que se sucedieron en la historia española durante la invasión francesa, repercutieron intensamente en la vida de la comunidad y en las obras de arte que poseían. El P. Carlos Corona, monje cartujo de Las Cuevas, escribió una breve memoria de los aciagos sucesos e infortunios que padecieron los religiosos de su monasterio desde 1810 , año en el que huyeron del mismo, hasta 1812 en que regresaron y les fue devuelto el convento en lamentables condiciones de conservación. En su relato expresa claramente cómo se salvó el sagrario y otras obras de arte, gracias a la protección que les dispensó el Gobemador del Alcázar, Mariscal de Campo D. Eusebio Herrera (18).

Estas noticias son veridicas, pues muchas de las obras expropiadas por los franceses fueron llevadas a los Reales Alcázares (esculturas, pinturas y plata), y entre ellas figuraron los retablitos de Pineda con relieves de Roldán. Al parecer, el mencionado Gobernador reservó el Santo Cristo de Martínez Montañés, el archivo, la sillería de coro y los relieves del sagrario, todo lo cual fue devuelto a los cartujos en 1814. Sin embargo, los monjes no volvieron a colocar los relieves en su anterior emplazamiento (en el Sancta Sanctorum), sino en una dependencia vecina a la sacristía denominada Capilla de Las Cuevas. En el sagrario propiamente dicho se montó en 1820 un retablo de tipo barroco, del artista Juan Gutiérrez, que Cuartero define como "churrigueresco" (19), de acuerdo a los comentarios que se hicieron sobre esta obra en el siglo XIX. La Cartuja quedó en lamentables condiciones al ser abandonada por los franceses, quienes utilizaron como cuartel para sus tropas la zona del convento, mientras que la iglesia con sus dependencias vecinas, sirvieron de almacén de viveres y bodega.

Desde que la comunidad volvió a ocupar su casa, comenzó la limpieza y reconstrucción del monasterio; en poco tiempo recuperaron su aspecto anterior los claustros y Sala del Capítulo (donde provisionalmente celebraban los cultos), pues la-iglesia necesitaba más reparaciones. Cuatro años tardaron los trabajos de restauración, de modo que sólo pudo abrirse al público el 6 de octubre de 1816, aunque sin el esplendor que tuvo en los siglos precedentes. Las noticias que da González de León en 1844 permiten confirmar la ejecución de un nuevo retablo mayor que tenía un arco al centro por el que se

(18) Gómez Imaz, M.: Un manuscrito inédito (1808-1816) proveniente del archivo del Monasterio de Santa María de Las Cuevas de Sevilla. Sevilla, 1917. Pág. 30.

(19) Cuartero y Huerta, B.: Op. cit. T. Il. Pág. 614. 
veía parte del consabido sagrario situado a su espalda. Este Sancta Sanctorum fue el que renovó en 1815 José Gutiérrez, quien dispuso un interior sumamente adornado de "mil labores prolijas y doradas", con un pequeño altar sobre el cual estaba el tabernáculo con-las Sagradas Formas y realzando el conjunto interior un farol de plata que lo iluminaba y el pavimento de ébano con incrustaciones de plata que debió rehacer el mencionado autor (20). No hay referencia a la rica custodia de Pina ni de los pequeños retablos de Pineda con las esculturas de Roldán, lo que ratifica las noticias que recogen Córdoba y Cuartero en el sentido de que los dichos retablitos se colocaron en otra dependencia vecina a la sacristía y no se repusieron en el lugar para el que habian sido hechos.

La desamortización de Mendizábal decretada en 1835, obligó a la dispersión de la comunidad y las obras de arte que restaban se repartieron por museos, catedrales y colecciones privadas. En 1838 el monasterio fue adquirido por D. Carlos Pickman, primer Marqués de este título, y fue convertido en fábrica de lozas y cerámica. La iglesia quedó vacía y las obras de arte que guardaba se trasladaron a una capilla de amplias dimensiones que fue habilitada para el culto; mientras que junto a la sacristía en la pequeña capilla de Las Cuevas permanecieron los retablos y relieves del sagrario de 1676. Ahí alcanzó a verlos D. José Gestoso en 1892 y dice sobre el particular. "...junto a la sacristia habia una capillita en uso... profusamente adornada con follajes, columnas salomónicas y otros ornatos tallados y dorados que sirvió de tabernáculo en la capilla del Sagrario de la iglesia grande" (21). No menciona los nombres de los artistas que hicieron estas obras, pero no cabe duda que se refiere a los ya citados Pineda y Roldán. En su tiempo la iglesia continuaba sin culto y no cita para nada el sagrario de 1815.

Es curioso este olvido de Gestoso, pues de seguro que conoció los datos proporcionados por Palomino y los autores antes citados, lo que puede estimarse, quizá, como consecuencia del desdén que tuvieron los eruditos e historiadores del siglo XIX por las recargadas omamentaciones barrocas. En cambio, Cascales Muñoz, sí cita las obras de Roldán en el sagrario de la cartuja, pero como "estatuas", lo que es erróneo, pues son relieves, aunque da la fecha exacta de ejecución (22). Es posible que efectuase esta designación

(20) González de León, F.: Noticia artistica de todos los edificios públicos de esta muy noble Ciudad de Sevilla. Sevilla, 1973. Págs. 591 y 592.

(21) Gestoso Pérez, J.: Sevilla Monumental y Antistica. T. Ill. Sevilla, 1982. Pág. 528.

(22) Cascales Muñoz, M.: Las Bellas artes plásoicas en Sevilla. T. II. Toledo, 1929. Pág. 32. 
por no haber visto las obras en cuestión y se limitase a seguir los datos proporcionados por escritores anteriores; 0 , tal vez, porque en su tiempo los retablos del sagrario viejo estaban desmontados parcialmente, como, al parecer permanecieron hasta 1947, año en el que fueron donados al Padre Arteche para que los llevara a la cartuja de Jerez y los colocase en el sagrario de ese renovado templo.

La cartuja de Jerez había permanecido abandonada durante muchos años, pero en los siglos del barroco fue uno de los monasterios más espléndidos de la Orden. Antonio Ponz la visitó a fines del siglo XVIII y comenta que el templo era de una nave gótica de buenas proporciones y que el retablo con pinturas de Zurbarán y esculturas de José de Arce, era de lo mejor del recinto. Añade que en los lados del dicho retablo, había dos puertas que conducían al Sagrario, en las cuales pintó Zurbarán los ángeles turiferarios (hoy en el Museo de Bellas Artes de Cádiz) y que a continuación se abrían dos pasillos que convergian en una pequeña pieza muy aseada, los que tenían pinturas de religiosos de la Orden de tamaño natural, admirablemente pintados (23). No dice nada del exorno del pequeño recinto que hacía de sagrario, sólo que era "muy aseado", pero coṇfirma la tesis de tener esta iglesia —como todas las de los monjes cartujos hispanos- el Sancta Sanctorum en el lugar acostumbrado entre el muro de cabecera y el altar mayor.

Romero de Torres al describir el cenobio jerezano en 1908 comenta que parte del edificio estaba en ruinas, caso de la sacristia, y que en la iglesia sólo quedaba el espacio del coro, pero no la magnífica sillería que fue trasladada a Jerez. No restaba nada del retablo ni del sagrario, aunque sí el espacio del ábside en el que estuvieron colocados (24). Este desolador aspecto del monasterio lo confirma el cronista de Jerez D. Manuel Esteve Guerrero en 1933, quien su Guía artística de la ciudad, se lamenta de que en el templo sólo quedaban "...los muros fríos y desmantelados..." (25).

Los protocolos cartujanos del tantas veces citado manuscrito del $\mathrm{P}$. Rincón, dan noticias de que durante el priorato del P. Blas Domínguez en La Defensión, hacia 1660, se hizo el sagrario, después de estar terminado y colocado el magnífico retablo de Arce y Zurbarán; pero añade el expresado documento, que este prior - procedente de Sevilla- emprendió costosas obras en su segundo priorato (entre 1665 y 1668), por lo que se le nombraron

(23) Ponz, A.: Op. cit. T. XVII. Págs. 276 y 277.

(24) Romero de Torres, E.: Catálogo Monumental de Espana: Provincia de Cádiz (1908-1909). T. I. Madrid, 1934. Pág. 434.

(25) Esteve Guerrero, M.: Jerez de la Frontera (gula oficial de Jerez), 1933. Pág. 218. 
dos visitadores que examinaron sus cuentas, y aunque lo absolvieron de culpa, lo devolvieron a su cartuja sevillana de Las Cuevas, donde ya antes había sido Prior (26) y había encargado precisamente la decoración de la sacristía a Pedro Roldán (1655), según vimos con anterioridad.

El estudio que efectuó César Pemán en 1950 del antiguo retablo de esta cartuja, se ciñe a la descripción comentada de Ponz y la del fraile jerónimo Esteban Rallón, quien entre 1670 y 1680 -más o menos- escribió una Historia de Jerez de la Frontera que hace ligeras referencias del dicho retablo y puertas laterales que abrían a dos pasillos decorados con pilastras y pinturas de santos cartujos (27). Se señala el Sancta Sanctorum como edículo rectangular y en la planta que reconstruye Pemán, se advierte efectivamente el lugar que debió ocupar este otro sagrario que desapareció después de la desamortización de 1835.

Así pues, la tarea del P. Arteche era árdua, pero con admirable tesón consiguió restaurar el impresionante conjunto, hasta alcanzar el estado en que hoy se encuentra, aun cuando. todavía faltan por reconstruir algunas partes del extenso monasterio. La iglesia ha recuperado su espléndido aspecto con la consolidación y limpieza de los muros; reinstalación de la sillería de coro en su lugar correspondiente; nuevos altares laterales y en la capilla mayor se ha colocado el antiguo retablo del templo de La Merced de Sanlúcar de Barrameda, donado por la Casa Ducal de Medinasidonia, pero sin las pinturas de Roelas que lo adornaban originalmente, por lo que se han colocado otras que no descomponen del severo aire arquitectónico del retablo, y se han puesto en los intercolumnios, dos esculturas originales de Pedro Roldán, de tamaño natural que representan a San Hugo de Lincoln y San Hugo de Grenoble, que probablemente proceden de la de Sevilla y habrian sido realizadas para esas capillas laterales al presbiterio que se hicieron en 1676, al tiempo que el sagrario, según noticia de la que hemos dado cuenta en páginas precedentes.

El Padre Arteche encomendó la restauración de las piezas al escultor Rafael Barbero, y se colocaron en la forma usual, detrás del altar mayor. Barbero tuvo que hacer nuevas figuras de ángeles, pues sólo restaba uno de los originales, y reparar todas las figuras de los relieves, aun cuando prefirió dejar sin cabezas o sin manos a aquellas figuras que las habían perdido para evitar lo que significase nuevas composiciones o hacer añadidos.

(26) José Martln Rincon. Op. Cit. Fol. 650.

(27) Pemán Pemartín, C.: "La reconstucción del retablo de la Cartuja de Jerez de la Frontera". Archivo Espantol de Arte. T. XXIII. Madrid, 1950. Págs. 203-227. 
Las obras que se realizaron en la cartuja de Jerez en el s. XVII reformaron el ábside poligonal de la iglesia trazada poco después de la fundación (1476), de manera que adquirió forma de testero recto con dos estribos al centro que señalan el tramo central primitivo que cerraba la cabecera, y que es donde se formó el sagrario del P. Domínguez que comenta brevemente Ponz y en donde se ha colocado el sagrario procedente de la cartuja de Las Cuevas. De este modo ha quedado un recinto rectangular, entre los dos contrafuertes, cubierto con media naranja calada e iluminado por una gran claraboya circular y dos más pequeñas que se inscriben en dos de las cuatro pechinas sobre las que apoya la cúpula. Es evidente que los retablos y relieves que cubren todos los muros han tenido que acomodarse al espacio entre los estribos y retablo mayor, pero puede hacerse alguna idea de cómo fue el Sagrario de Las Cuevas -algo más amplio- por los retablos y relieves recuperados y por las referencias de Espinosa y Cárcel ya citadas.

Este autor comenta que el recinto covitano era de "tres varas en cuadro", o sea, que fue de planta cuadrada y de unos $2,80 \mathrm{~m}$. por lado y unos diez metros de alto aproximadamente. Añade que tres testeros estaban cubiertos de madera dorada, figurando altares y con relieves de diferentes temas alusivos a la Eucaristía. El cuarto lado tenía en sus partes bajas -en chaflán- las puertas de acceso, que eran de cristales y en la parte superior el gran arco o medio punto correspondiente al retablo mayor que hacía algo visible el Sancta Sanctorum o sagrario desde la nave de la iglesia, con esa sensación de transparencia del lugar sacro por excelencia, que tuvieron todos los templos cartujanos desde remotos tiempos. Al adaptarse el sagrario covitano al de la Defensión ha adoptado una planta ligeramente rectangular.

La estructura de esta habitación inicialmente cuadrilonga y coronada por cúpula con linterna, fue idea de Bernardo Simón de Pineda, y hoy puede admirarse en Jerez, pues los cambios no han sido sustanciales. El concepto espacial que desarrolla Pineda es el de una especie de baldaquino cerrado, con fuerza centrípeta y como si se tratara de un cofre o caja preciosa.

Las columnas salomónicas dispuestas en las esquinas de los retablos, convergen en las pechinas decoradas con cartabones y tienen al centro las figuras de los cuatro Evangelistas y sus símbolos parlantès. Las columnas de los altares, descansan sobre basamentos y breves resaltos que corresponden a las dimensiones del pequeño espacio. Los fustes son casi todos de seis espiras completas, con gargantas destacadas por estrangulamiento y por cinta del laurel que se adhiere a ella. Están ornadas de rosas, con hojas y tallos de sinuosos movimientos. Los capiteles compuestos son de volutas muy altas y en general todo aparece ricamente tallado con numerosos querubines y "putti" 
de inquietas posturas y miradas que dan animación al conjunto y flanquean los relieves de Roldán. El espacio aparece como abigarrado, pero con un simbolismo eucarístico en el que, además de los temas de los relieves, insisten las decoraciones de ristras de frutas turgentes, los ángeles con filacterias y las cartelas con inscripciones alusivas al Santísimo Sacramento.

Tanto en Sevilla como en Jerez, se han cuidado los efectos de luz que contribuye a crear o sublimar el espacio y producir una atmósfera de misterio. En el actual sagrario la luz ténue se filtra por la cúpula de material calado relleno con trozos de cristal, linterna con vidrieras y por las tres claraboyas circulares mencionadas. Los retablos de quebradas líneas fueron dorados y policromados por Miguel Parrilla, pintor que también hizo varias pinturas en lienzo para la Cartuja. La reciente restauración ha recuperado los relucientes destellos de un oro viejo de ricas calidades, lo que ayuda a acentuar el sentido iconológico de lugar recogido y secreto, o sancta sanctorum de aureas refulgencias.

En el testero del sagrario hay un retablito que conserva estructuras del antiguo templete con baldaquino que Pineda hizo para cobijar una custodia. Primero se utilizó la antigua del s. XV y luego la de Juan Laureano de Pina. Esta ha desaparecido, y el dicho retablo tiene muchos añadidos, pero sigue siendo el lugar central del conjunto, pues es el que posee el tabemáculo, hoy de labores modernas. Este templete o tabernáculo está dorado, y en él se aprecia claramente la diferencia de talla y tratamientos de las figuras esculpidas en relieve, que son, una custodia con sol radiante y debajo una nube de tres querubines. En la parte superior, en las pechinas, se ven los Evangelistas San Juan y San Marcos.

En el muro lateral derecho está el retablo de Pineda con relieves de Roldán que representan: las Bodas de Caná al centro y en los intercolumnios historias biblicas como alusiones al pan del cielo que administran los ángeles a los pobres, y la caída del Maná como inequívoca representación de la Eucaristía. El central se encuentra muy estropeado, pero se observa la hábil disposición, algo teatral, que suele emplear Roldán en sus personajes, y la correcta utilización de fondos con perspectivas, así como detalles secundarios de la escena. En los laterales las figuras poseen tratamientos anatómicos de buena factura y cabelleras bien dibujadas, al igual que las expresiones de los rostros y pliegues de las vestiduras.

En el muro lateral derecho está el tercer retablito de Pineda con los relieves de Roldán que representan al centro la Ultima Cena, y en los intercolumnios las historias del trigo y el vino como símbolos eucarísticos. 
El central es de fondo arquitectónico parecido al de las Bodas, pero con la inclusión de dos servidores que animan los vacíos de esas zonas. Los Apóstoles están dispuestos en tomo a Jesús y a una mesa elíptica. Los rostros están mutilados, pero algunos trozos mejor conservados, dan idea de la calidad del relieve y elementos que sobriamente dispone sobre la mesa. Las historias laterales, tienen cada una dos personajes tratados con buenas facturas, las que se advierten pese a los repintes que aún quedan y las mutilaciones que exhiben. En uno se representa el momento en el que se entregan las espigas de trigo para hacer el pan como alimento de los pobres, y en el otro es el vino que se escancia, como el agua, desde una vasija grande a un recipiente pequeño; simbolizan la obligación de dar de comer y beber a los que tienen hambre y sed con indudables alusiones a la Eucaristía .

El cuarto lado corresponde a la trasera del retablo mayor y sólo tiene decoraciones probablemente aprovechadas de los anteriores trabajos de Pineda y otros que se acondicionaron para este lugar, dada la mayor altura de la homacina central del dicho retablo.

A diferencia de los sagrarios de Valencia y Granada, estudiados por Alejos Morán y Rodríguez Gutiérrez de Ceballos (28), el programa iconográfico de la cartuja de Las Cuevas es muy sencillo; no posee grandes composiciones en honor de la Eucaristía que incluyan historias, esculturas exentas y yeserías, y, estructuralmente, todo es como más recoleto e íntimo; tan rico como las barrocas facturas que triunfaron en el $\mathrm{s}$. XVIII, pero más cerrado e independiente del retablo mayor.

Sin duda es más extensa la lectura iconológica que puede hacerse de este hermoso conjunto barroco recreado en Jerez con aprovechamiento de las historias bíblicas y evangélicas que se han comentado, pero no podemos alargarnos más. Las líneas que se han escrito en este breve trabajo pueden dar testimonio de la calidad de las tareas que realizaron conjuntamente Pineda. Roldán y Parrilla, y dar conocimiento del afortunado traslado a la cartuja de la Defensión de este sagrario, uno de los más antiguos del período barroco, y que viene a aumentar la producción de estos artistas, así como el catálogo del patrimonio artístico andaluz.

(28) Alejos Morán, A.: La Eucarista en el arte valenciano. Valencia, 1977 y Rodrlguez Gutiérrez de Ceballos, A.: Op. cit. Págs. 91-97. 


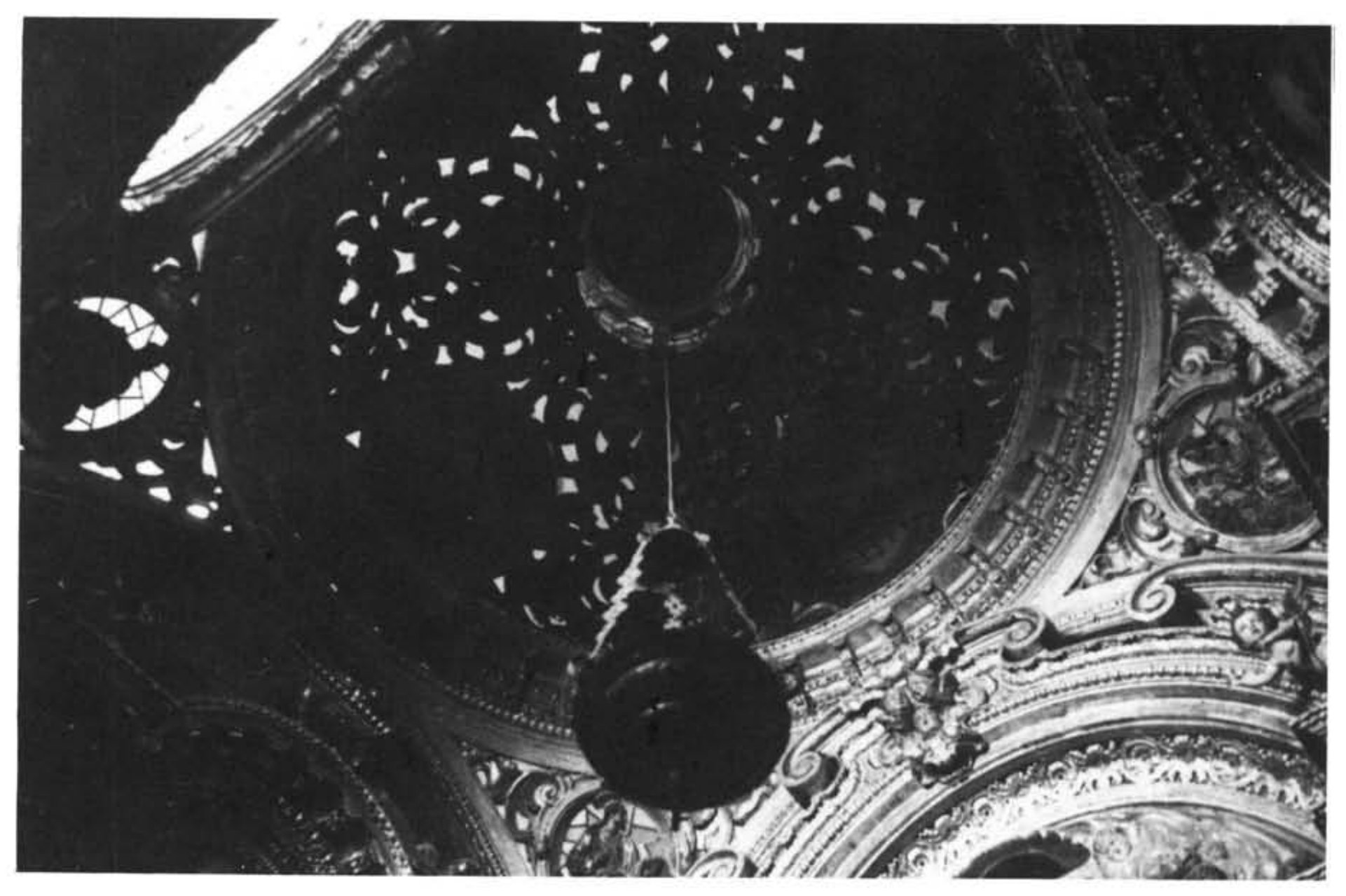



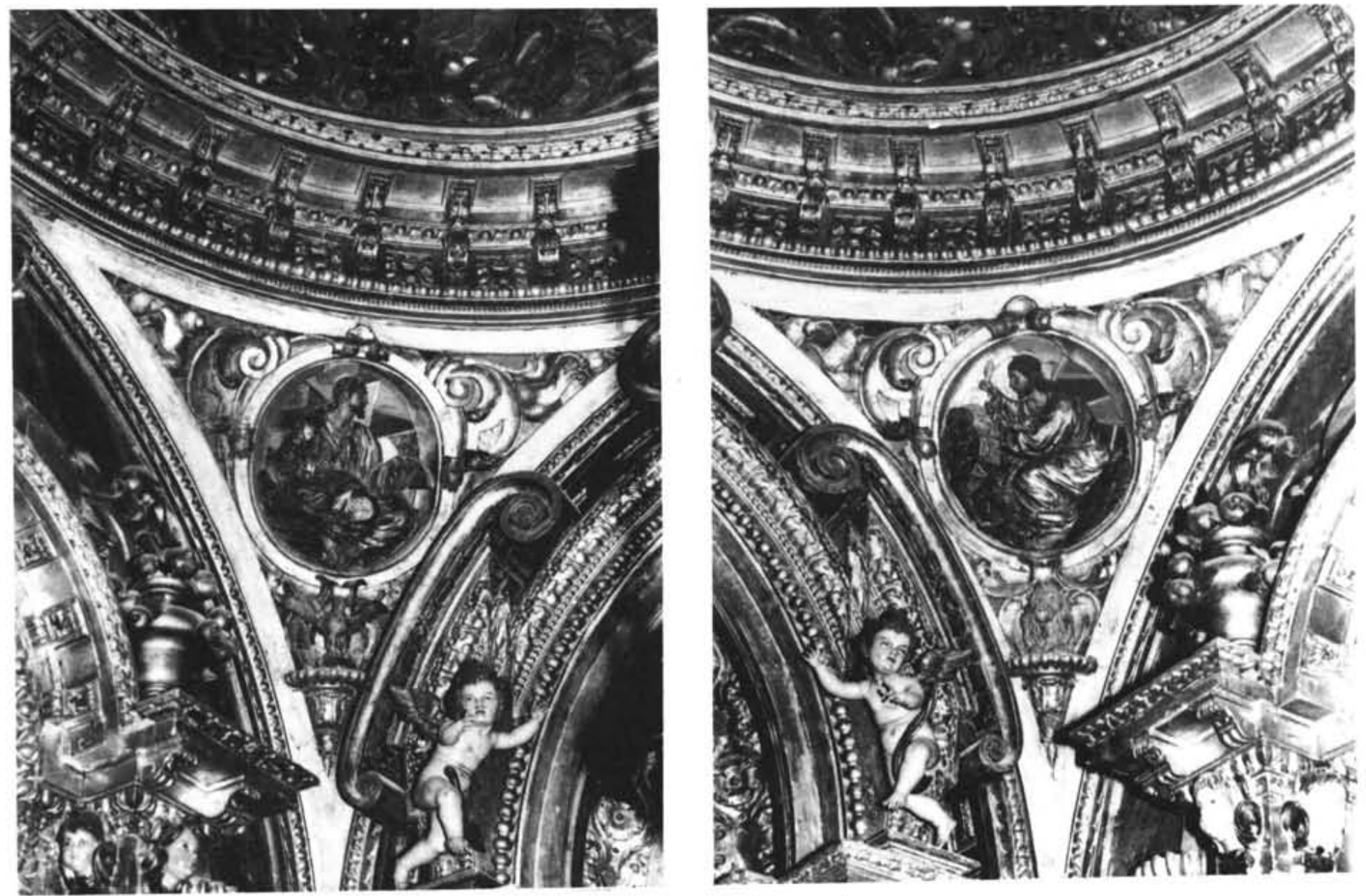

Pechinas y parte alta del Sagrario 


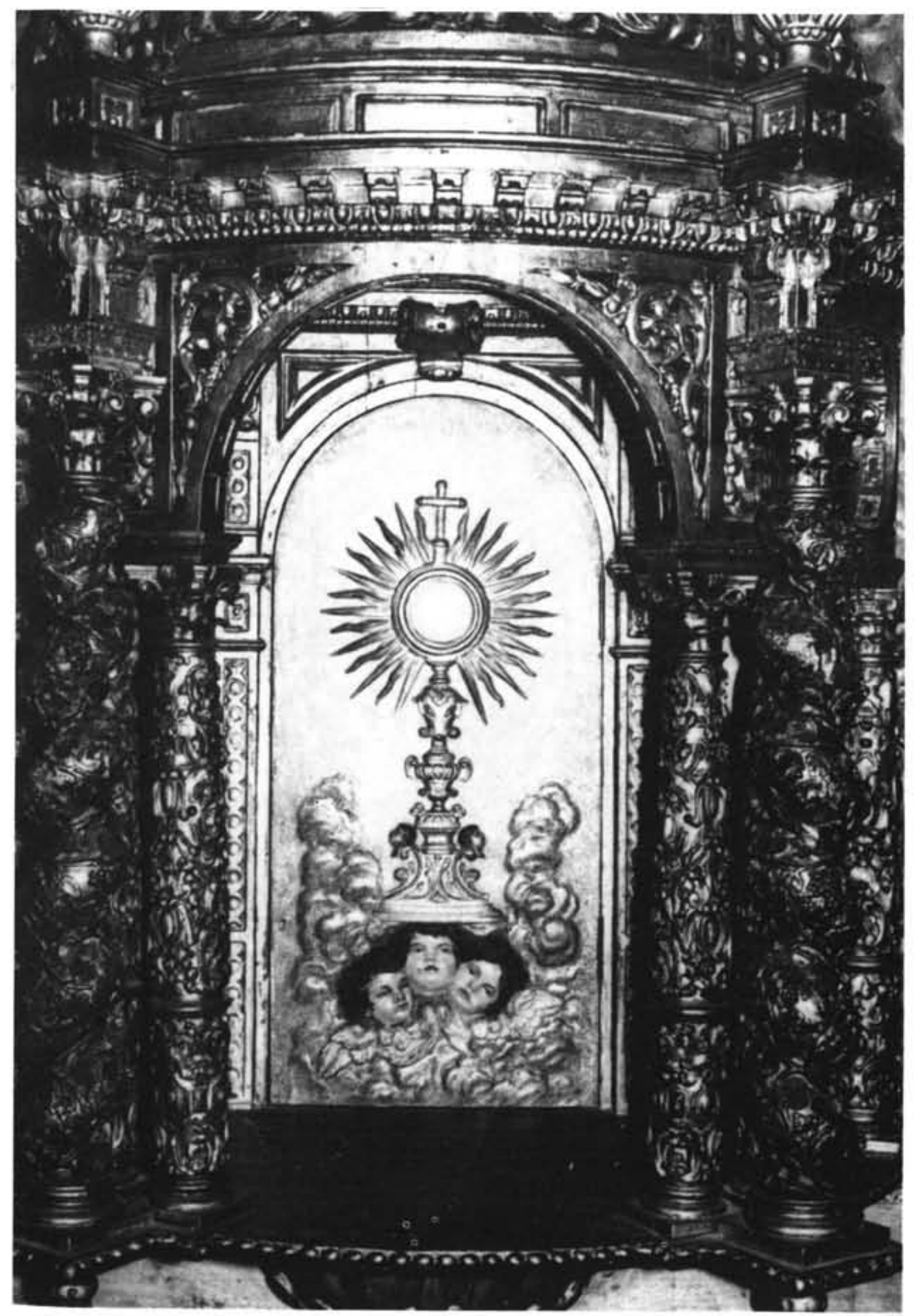

Tabernáculo del Sagrario 

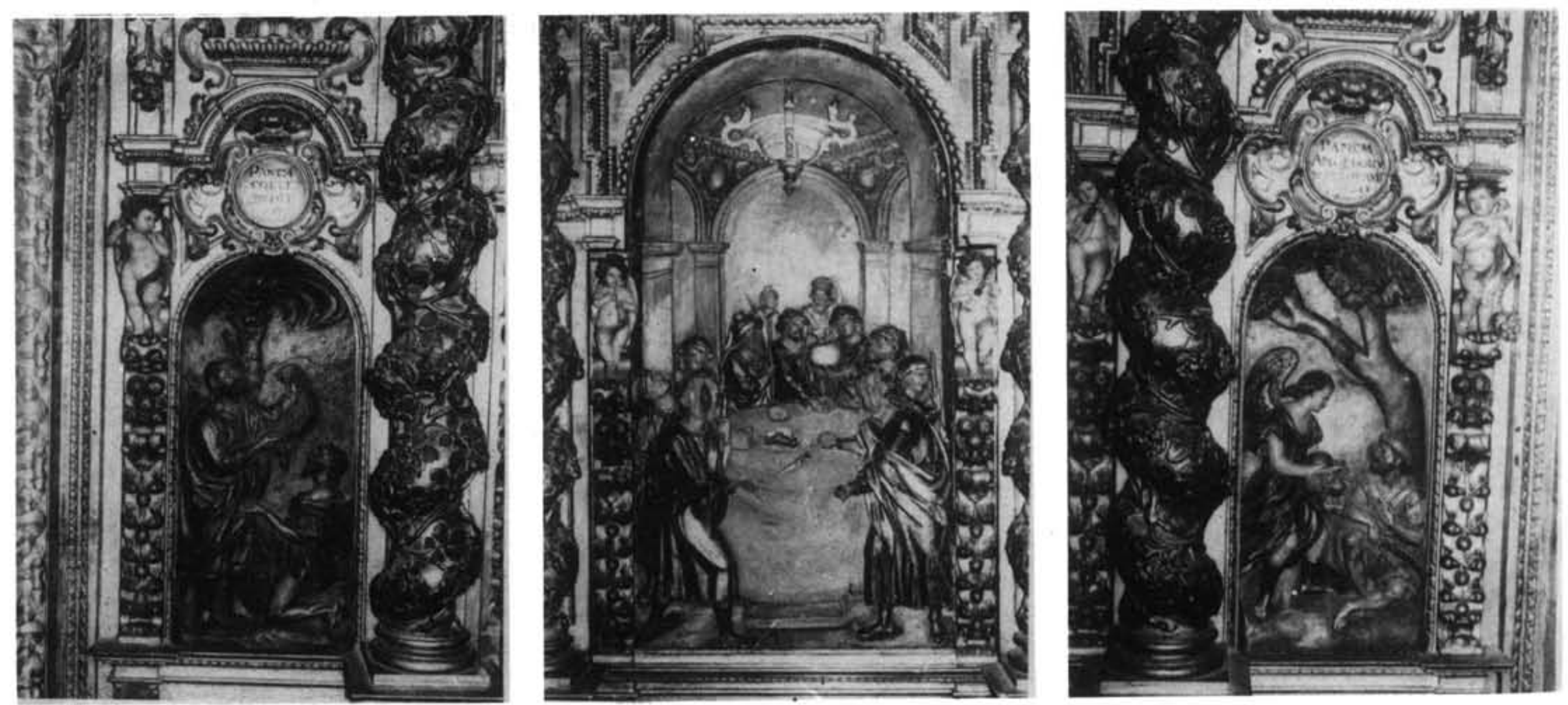

Bernardo Simón de Pineda-Pedro Roldán. Retablo del muro derecho del Sagrario 

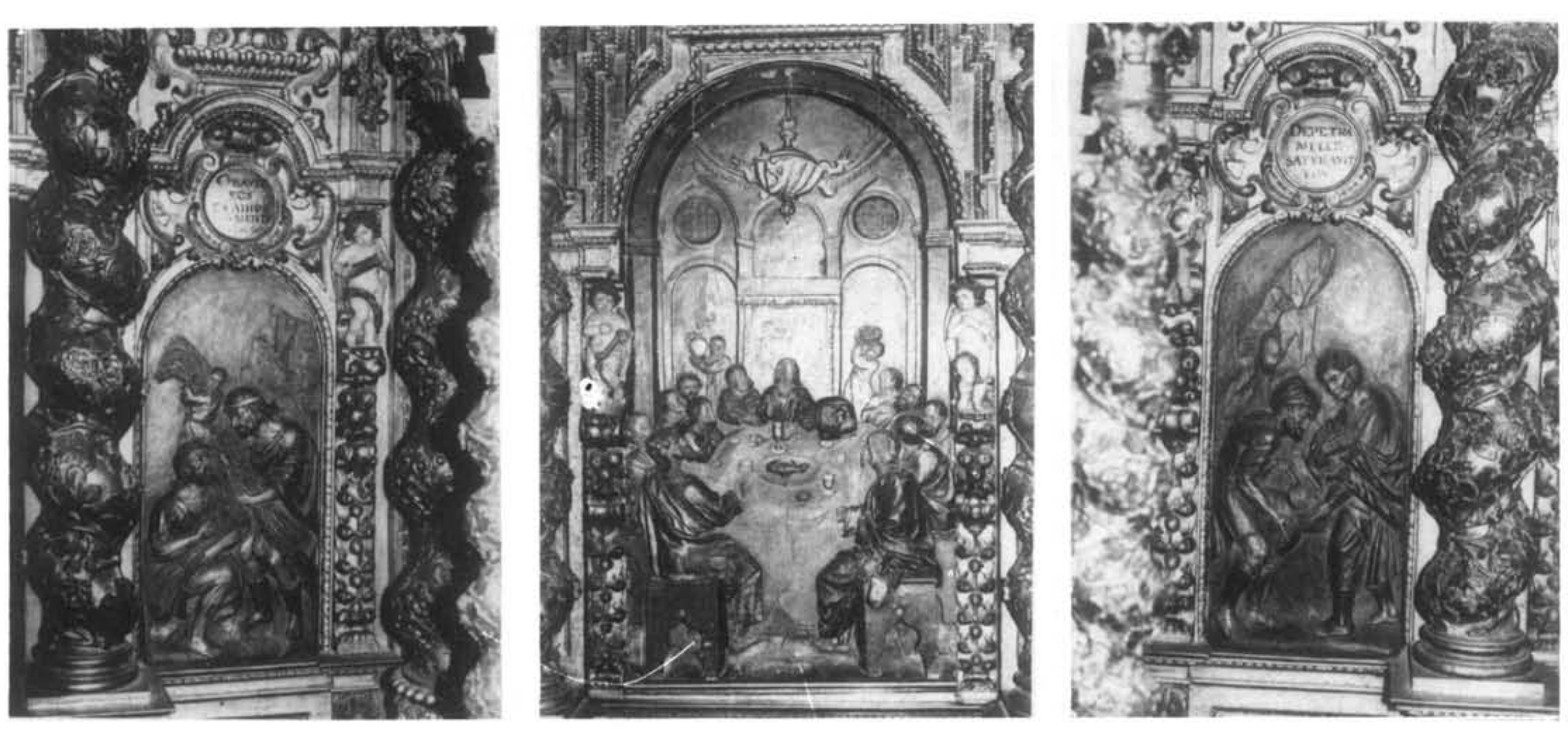

Bernardo Simón de Pineda-Pedro Roldán. Retablo del muro izquierdo del Sagrario 